\title{
Intra-articular therapy in osteoarthritis
}

\section{Uthman, J-P Raynauld, B Haraoui}

Postgrad Med J 2003;79:449-453

The medical literature was reviewed from 1968-2002 using Medline and the key words "intra-articular" and "osteoarthritis" to determine the various intra-articular therapies used in the treatment of osteoarthritis. Corticosteroids and hyaluronic acid are the most frequently used intra-articular therapies in osteoarthritis. Other intra-articular substances such as orgotein, radiation synovectomy, dextrose prolotherapy, silicone, saline lavage, saline injection without lavage, analgesic agents, non-steroidal anti-inflammatory drugs, glucosamine, somatostatin, sodium pentosan polysulfate, chloroquine, mucopolysaccharide polysulfuric acid ester, lactic acid solution, and thiotepa cytostatica have been investigated as potentially therapeutic in the treatment of arthritic joints. Despite the lack of strong, convincing, and reproducible evidence that any of the intra-articular therapies significantly alters the progression of osteoarthritis, corticosteroids and hyaluronic acid are widely used in patients who have failed other therapeutic modalities for lack of efficacy or toxicity. As a practical approach for a knee with effusion, steroid injections should be considered while the presence of symptomatic "dry" knees may favour the hyaluronic acid approach. The virtual absence of serious side effects, coupled with the perceived benefits, make these approaches attractive.

See end of article for authors' affiliations

Correspondence and reprint requests to: $\mathrm{Dr}$ Imad W Uthman, American University of Beirut Medical Centre, PO Box:

1 13-6044, Hamra 11032090, Beirut, Lebanon;

iuthman@aub.edu.lb

Submitted

26 November 2002

Accepted 17 March 2003
O teoarthritis is a disease characterised by mixture of degradative and reparative processes in the articular cartilage, subchondral bone associated with marginal osteophyte formation, and low grade inflammation. Osteoarthritis involves mainly the hips, knees, spine, and the interphalangeal joints. Its clinical presentation is usually monoarticular or oligoarticular with fluctuations in intensity and localisation over time. It is therefore logical to consider local therapeutic modalities in order to avoid untoward systemic effects. Several compounds have been used intra-articularly in open label and in double blind randomised clinical trials. In this article we review the various intra-articular therapeutic modalities used in the treatment of osteoarthritis.

\section{CORTICOSTEROIDS}

Corticosteroids are very potent antiinflammatory agents. Intra-articular injections have been used for nearly five decades for the symptomatic treatment of osteoarthritis. ${ }^{1}$ A survey of rheumatologists in the US suggested that more than 95\% use this treatment sometimes and more than half of them, frequently. ${ }^{2}$ Intraarticular corticosteroids are also recommended in the recent American College of Rheumatology guidelines for the management of acute knee pain in patients with osteoarthritis. ${ }^{3}$

Corticosteroids exert their anti-inflammatory action by interrupting the inflammatory and immune cascade at several levels including: impairment of antigen opsonisation, interference with inflammatory cell adhesion and migration through vascular endothelium, interruption of cell-cell communication by alteration of release or antagonism of cytokines (interleukin-1), impairment of leukotriene and prostaglandin synthesis, inhibition of production of neutrophil superoxide, metalloprotease and metalloprotease activator (plasminogen activator), and decreased immunoglobulin synthesis. ${ }^{4}$

Earlier studies have reported that corticosteroids injections may suppress cartilage proteoglycan synthesis, worsen cartilage lesion, or even cause degenerative lesions in normal cartilage. ${ }^{5}$ In more recent reports, using animal model (rabbits and guinea pigs) of osteoarthritis, several investigators have reported that low dose intra-articular corticosteroids (sufficient to suppress catabolism) normalised cartilage proteoglycan synthesis and significantly reduced the incidence and severity of cartilage erosions and osteophyte formation. ${ }^{6}$

In a study using the Pond-Nuki dog model of osteoarthritis, an animal model which closely resembles the changes observed in human osteoarthritis, intra-articular injection of low dose triamcinolone acetonide ( $5 \mathrm{mg}$ ), a long acting corticosteroid preparation, reduced osteophyte formation and cartilage lesions and exerted a protective effect on cartilage histological changes (confined the spread of cartilage erosions, reduced the formation of fissures and cell clones, and preserved matrix proteoglycans). ${ }^{6}$ In a more recent study, also using a dog experimental model of osteoarthritis, intra-articular injections with methylprednisolone acetate (MPA) significantly reduced the incidence and size of osteophytes and the severity of cartilage lesions; this was associated with a decrease in chondrocyte stromelysin synthesis. $^{7}$ The beneficial effect of corticosteroids on cartilage can be due to several possible mechanisms: in vivo suppression of metalloproteases synthesis (probably by suppression of gene

Abbreviations: $k D$, kilodalton; MPA, methylprednisolone acetate; NaPP, sodium pentosan polysulfate; NSAIDs, non-steroidal anti-inflammatory drugs; WOMAC, Western Ontario and McMaster Universities Osteoarthritis Index 
expression), decreasing the synthesis of possible physiological activators such as plasminogen activator/plasmin or by increasing the level of tissue inhibitors of metalloproteases, or by suppression of the synthesis of synovial factors such as interleukin-1..$^{6-8}$

In humans, repeated corticosteroid injections in knees of patients with chronic arthritis presented no evidence of destruction or accelerated deterioration. ${ }^{9}$ In a recent study, a single intra-articular injection of triamcinolone acetonide to patients with knee osteoarthritis provided short term pain relief. ${ }^{10}$ Increased benefit was associated with both clinical evidence of joint effusion and successful aspiration of synovial fluid at the time of injection. ${ }^{10}$

To demonstrate the difference in outcome and rate of cartilage degradation among patients with knee osteoarthritis treated with intra-articular corticosteroid injections, we have studied 70 patients fulfilling the American College of Rheumatology criteria for primary knee osteoarthritis who were randomly chosen to receive intra-articular injections of a corticosteroid ( $40 \mathrm{mg}$ triamcinolone acetonide ) or a vehicle, at three month intervals, for a prospective period of two years. Patients with a standing radiograph showing a joint space width of the knee internal compartment of less than $2 \mathrm{~mm}$ were excluded. Conventional treatment (analgesics and non-steroidal anti-inflammatory drugs (NSAIDs) except indomethacin) was prescribed according to the practitioner's usage and was systemically recorded. The radiological progression of joint space narrowing of the injected knee over two years was our primary outcome variable. The progression was assessed blindly at one and two years of treatment with the validated Buckland-Wright protocol. Clinical evaluation of the patients using validated measures Western Ontario and McMaster Universities Osteoarthritis Index (WOMAC), global assessments with visual analogue scales, 50 foot walking time) was also conducted every three months by blinded investigators; 68 patients completed the study. Baseline characteristics between the two groups regarding clinical and anatomical measurements were similar. ${ }^{11}{ }^{12}$ No difference was noted between the two treatment groups at one and two years with respect to loss of joint space over time $(p=0.57)$. At the one and two year follow up evaluations, the patients injected with triamcinolone acetonide showed a trend toward greater symptom improvement, especially at the first year follow up, for the WOMAC pain subscale, night pain assessment, and the range of movement $(p=0.05)$ compared with patients injected with saline. Moreover, using area under the curve analyses, knee pain and stiffness were significantly improved throughout the two year study, by repeated injections of triamcinolone acetonide compared with saline injections $(\mathrm{p}<0.05))^{12}$

Different corticosteroid formulations have been used over the years, with similar general efficacy: triamcinolone acetonide, MPA, and prednisolone acetate were administered in single or multiple repetitive injection regimens. ${ }^{10-20}$ In one trial, triamcinolone acetonide had a longstanding effect superior to betamethasone ${ }^{16}$; this observation, however, was not shared by other investigators who demonstrated a short lived beneficial effect not lasting beyond one week. ${ }^{15} 1820$ Despite several observed flaws in the design of these trials, valuable information has been gathered, especially regarding the short term safety of this approach. Moreover, the aspiration of the effusion, when present, seems to bring additional short term clinical benefit to triamcinolone acetonide injections. ${ }^{10}$ Despite their wide use in clinical practice, no predictors of response could be identified in two recent randomised double blind trials. $^{10} 20$

The perceived efficacy and lack of major toxicity have made intra-articular corticosteroid injections one of the mainstays of the management of osteoarthritis, in particular, osteoarthritis of the knee.

\section{HYALURONIC ACID}

Viscosupplementation is a novel, safe, and possibly effective form of local treatment for osteoarthritis. ${ }^{21}$ It aims at supplying replacement hyaluronic acid into the joint space to return the elasticity and viscosity of the synovial fluid to normal. ${ }^{22}$ Hyaluronic acid, a polysaccharide consisting of a long chain of disaccharides ( $\beta$-D-glucuronyl- $\beta$-D-N-acethylglucosamine), is a natural component of cartilage and plays an essential part in the viscoelastic properties of the synovial fluid. Because of its hyaluronic acid content, joint fluid acts as a viscous lubricant during slow movement of the joint, as in walking, and as an elastic shock absorber during rapid movement, as in running. It is considered not only a joint lubricant, but also a physiological factor in the trophic status of cartilage. Hyaluronic acid has a very high water binding capacity: when $1 \mathrm{~g}$ of hyaluronic acid is dissolved in physiological saline, it occupies three litres of solution. ${ }^{23}$ The estimated total hyaluronic acid in a human knee joint is from $4-8 \mathrm{mg} .^{23}$

Intra-articular injections of hyaluronic acid with a molecular weight between 500 and 750 kilodaltons (kD) have been studied using corticosteroid injections ${ }^{24-28}$ or NSAIDs ${ }^{29}$ as control treatment, and by conducting placebo controlled clinical trials. ${ }^{30-37}$ These studies suggested that intra-articular injection of hyaluronic acid may improve the clinical condition and have a long term beneficial effect in knee osteoarthritis patients especially if osteoarthritis was less than moderate in grade. ${ }^{30-37}$ A review by Maheu looked at five different clinical trials, comparing different regimens of Hyalgan (a hyaluronan preparation; Sanofi-Synthelabo) versus corticosteroid injections in the osteoarthritis knee, with follow ups from 2-12 months. ${ }^{38}$ One study showed initial superiority of Hyalgan over corticosteroid injections and in three studies, equal efficacy over time. The fifth study used a combination of Hyalgan and corticosteroid injections initially. The corticosteroid injections seemed to increase the long term efficacy of the hyaluronic acid suggesting that the combination of these two local treatments would be promising. In a recent randomised clinical trial of 495 patients with osteoarthritis of the knee, Altman et al demonstrated that one intra-articular injection of Hyalgan each week for a period of five weeks is at least as effective as continuous treatment with naproxen for 26 weeks, with fewer adverse reactions. ${ }^{39}$ The long term structure modifying properties of Hyalgan were investigated through a double blind randomised placebo controlled trial using a standardised arthroscopic score after one year of follow up. Hyaluronic acid proved superior to placebo in two out of three parameters used to quantify the severity of osteoarthritis lesions. ${ }^{40}$

On the other hand, however, a double blind placebo controlled study involving 91 patients with radiologically confirmed knee osteoarthritis concluded that intra-articular administration of $750 \mathrm{kD}$ hyaluronic acid offered no significant benefit over placebo during a five week treatment period, but incurred a significantly higher morbidity. ${ }^{41}$ Furthermore, in a study that evaluated the effect of joint lavage with lactated Ringer's solution in 23 patients, the secondary goal was to determine if any additional benefit could be obtained by injecting the knee with hyaluronic acid after washout treatment. ${ }^{42}$ Improvement was noted at one and two year follow ups; however, there were no statistically significant differences in outcome for the hyaluronic acid and placebo groups. A one year double blind control study involving 52 patients compared the effect of intra-articular injections of hyaluronic acid and placebo, both administrated weekly for five weeks. ${ }^{43}$ Though both groups improved from baseline, there was no statistically significant difference in any of the relevant variables at any time point. Another large randomised double blind placebo controlled trial also found no significant difference at 20 weeks between the two groups when compared to their baseline evaluation. However, once stratified according to 
age and disease severity, hyaluronic acid proved more efficacious than placebo for patients over 60 years of age who had the most severe knee osteoarthritis. ${ }^{44}$

Intra-articular injection with hyaluronic acid is a relatively safe approach; however, some adverse events have been reported. In a retrospective study of 336 patients treated by five Canadian rheumatologists over 2.5 years ( 1537 injections involving 458 knees) it was suggested that the incidence of local adverse events after injection of hylan G-F 20 was relatively low and was influenced by the injection technique, ${ }^{45}$ and with a medial approach and a partially flexed knee, the incidence was $5.2 \%$; with a straight medial approach, $2.4 \%$; and with a straight or lateral approach, $1.5 \%$. In another study of 22 patients who received a total of 88 injections in 28 knees, post-injection "flares" occurred in $27 \%$ of patients and after $11 \%$ of injections. ${ }^{46}$ In some cases, acute synovitis was associated with joint swelling lasting up to three weeks. ${ }^{47}$ Other rare side effects included haemarthrosis, ${ }^{40}$ muscle pain, ${ }^{48}$ and pseudogout. ${ }^{49}{ }^{50}$

In conclusion, in the majority of studies, a clinical benefit of treatment was reported compared with the injected control group. Compared with treatment with local corticosteroids, hyaluronic acid showed equal pain relief in the first few weeks after therapy, with hyaluronic acid demonstrating more sustained benefit up to 60 days. ${ }^{51}$ In all trials reporting adverse effects, the primary adverse effect with hyaluronic acid was pain at the injection site. ${ }^{51}$ Although considerable evidence supports the positive effects of hyaluronic acid on joint cellular and immunological function there is still insufficient information to permit a conclusion concerning the effect of this treatment, if any, on the progression of osteoarthritis in humans. ${ }^{52}$

\section{OTHER INTRA-ARTICULAR THERAPIES FOR KNEE OSTEOARTHRITIS}

Other substances such as orgotein, radiation synovectomy (dysprosium-165hydroxide macroaggregate, yttrium-90 silicate), dextrose prolotherapy, silicone, saline lavage, saline injection without lavage, analgesic agents (bupivicaine, morphine), NSAIDs (tenoxicam, indoprofen, phenylbutazone), glucosamine, ${ }^{53}$ somatostatin, ${ }^{54}$ sodium pentosan polysulfate $(\mathrm{NaPP}),{ }^{55}$ chloroquin, ${ }^{56}$ mucopolysaccharide polysulfuric acid ester, ${ }^{57}$ lactic acid solution, ${ }^{58}$ thiotepa, ${ }^{59}$ cytostatica (thiotepa, azetepa, and osmium acid), ${ }^{60}$ have been investigated as potentially therapeutic in the treatment of arthritic joints. Orgotein is the pharmaceutical form of the bovine enzyme $\mathrm{Cu}-\mathrm{Zn}$ superoxide dismutase. The antiinflammatory properties of orgotein were discovered in $1965 .^{61}$

A randomised double blind study comparing orgotein injections with intra-articular MPA injections found that orgotein could be used safely and effectively without serious adverse reactions. ${ }^{62}$ The efficacy of orgotein was compared to that of betamethasone over a one year period in 419 patients with knee osteoarthritis. ${ }^{63}$ Though betamethasone acted more quickly, orgotein at low doses ( $4 \mathrm{or} 8 \mathrm{mg}$ ) was comparable to the corticosteroid from week 4 , and up to a year of follow up. The main adverse reactions to orgotein were pain, swelling, stiffness, prickling or burning sensations, skin rashes, or a feeling of heaviness at the injection site..$^{62}{ }^{63}$

An observational prospective study evaluating the effects of radiation synovectomy was conducted in 40 patients with knee osteoarthritis over a one year period. ${ }^{64} \mathrm{~A}$ marked improvement in pain and evaluation scores occurred at three months, but had disappeared by six months after treatment. The safety and efficacy of dysprosium-165 hydroxide macroaggregate was compared to yttrium-90 silicate for radiation synovectomy of the knee in a multicentre double blind clinical trial, with no significant difference in clinical response between the two treatment groups ${ }^{65}$ No clinically significant side effects were observed. ${ }^{65}$ Reeves and Hassanein in a randomised prospective double blind placebo controlled study of dextrose prolotherapy for knee osteoarthritis concluded that injection with $10 \%$ dextrose resulted in a statistically significant clinical improvement. ${ }^{60}$

Intra-articular silicone injections have been used in few studies. ${ }^{67-69}$ Wright et al conducted a pilot study in five patients, with a control group of 25 outpatients, to evaluate intraarticular silicone as an artificial lubricant for osteoarthritis joints. ${ }^{68}$ Sequential analyses showed a significant benefit from saline compared with silicone at one week follow up, and no significant difference at one month.

A randomised placebo controlled study with 20 patients was carried out to assess saline lavage of knee osteoarthritis versus intra-articular saline injection without lavage..$^{70}$ Though both groups showed improvement, knee washout conferred no further benefit. However, in a recent randomised single blind study, tidal knee irrigation with saline in 77 patients with knee osteoarthritis showed a greater reduction in pain than did conservative medical management. ${ }^{71}$ In a 24 week placebo controlled study in 98 patients, Ravaud et al compared joint lavage to a single corticosteroid injection and the combination of both interventions. ${ }^{72}$ Intra-articular corticosteroids had a beneficial effect on pain as early as the first week, but it was lost by week 12 . On the other hand, joint lavage had a delayed onset of action (week 4) but lasted up to the final 24 week evaluation.

Since pain is the main symptom in knee osteoarthritis, intra-articular analgesic agents were tested in three studies. In a single blind trial, 20 patients were randomised to receive either intra-articular bupivicaine or placebo ${ }^{73}$; the local anaesthetic agent had a short lived significant effect (less than 24 hours). In a crossover placebo controlled design, intraarticular morphine ( $100 \mathrm{mg}$ ) was shown to be superior to placebo and had a long lasting effect, up to nine days, which was the last evaluation period for this study. ${ }^{74}$ Stein $e t$ al examined intra-articular morphine in chronic arthritis in a randomised double blind comparison between intra-articular morphine ( 3 $\mathrm{mg})$, dexamethasone $(4 \mathrm{mg})$, and saline $(3 \mathrm{ml})$ in 44 patients with chronic inflammatory arthritis or osteoarthritis of the knee. ${ }^{75}$ They concluded that intra-articular morphine produces analgesia of similar magnitude to dexamethasone and it may have anti-inflammatory actions in chronic arthritis.

Trials on the intra-articular injection of NSAIDs have been reported by a number of investigators. A single tenoxicam intra-articular injection was also superior to placebo with no local side effects. ${ }^{76}$ Egsmose et al in a triple blind controlled study comparing the effect of IA indoprofen with placebo in hip joint osteoarthritis, did not find any superior effect of intra-articular indoprofen compared to placebo as regards pain relief or increased joint mobility. ${ }^{77}$ Moens and Moens tried intra-articular injection of phenylbutazone in a patient with gonarthrosis. ${ }^{78}$ Glucosamine was shown to be safe and provided a greater benefit than placebo. ${ }^{53}$ Somatostatin led to pain reduction and increased joint mobility with no reported adverse reactions. ${ }^{54}$ Finally, NaPP isolated from beechwood hemicellulose has anticatabolic effects in osteoarthritis by direct enzyme inhibition and gene expression alteration of metalloproteinases. One injection of NaPP each week for a period of four weeks was administered intra-articularly in 15 patients with knee osteoarthritis and they showed a greater improvement in pain and mobility, as well as synovial fluid viscosity, at two months compared with a control group 16 patients injected with saline ${ }^{55}$; however, data on long term efficacy and safety are not available.

\section{CONCLUSION}

Despite the lack of strong, convincing, and reproducible evidence that any of these intra-articular therapies significantly alters the short term outcome and even less so the progression of osteoarthritis, corticosteroids and hyaluronic acid 
are widely used in patients who have failed other therapeutic modalities for lack of efficacy or toxicity. As a practical approach for a knee with effusion, steroid injections should be considered, while the presence of symptomatic "dry" knees may favour the hyaluronic acid approach. The virtual absence of serious side effects, coupled with the perceived benefits, make these approaches attractive.

\section{Authors' affiliations}

I Uthman, Department of Internal Medicine, Faculty of Medicine, American University of Beirut, Beirut, Lebanon

J-P Raynauld, B Haraoui, Osteoarthritis Research Unit, Department of Rheumatology, Hôpital Notre-Dame, Centre Hospitalier de I'Université de Montréal, Montréal, Québec, Canada

\section{REFERENCES}

1 Menkes CJ. Intraarticular treatment of osteoarthritis and guidelines to its assessment. J Rheumatol 1994:21 (suppl 41):74-6.

2 Hochberg MC, Perlmutter DL, Hudson Jl, et al. Preferences in the management of osteoarthritis of the hip and knee: results of a survey of community-based rheumatologists in the United States. Arthritis Care Res 1996;9:170-6

\section{American College of Rheumatology Subcommittee on}

Osteoarthritis Guidelines. Recommendations for the medical management of osteoarthritis of the hip and knee: 2000 update. Arthritis Rheum 2000;43: 1905-15.

4 Wilder RL. Corticosteroids. In: Klippel JH, Cornelia WM, Wortmann RL, eds. Primer on the rheumatic diseases. Atlanta: Arthritis Foundation, 1997: 427-31.

5 Pelletier JP, Haraoui B, Martel-Pelletier J. Modulation of cartilage degradation in arthritic diseases by therapeutic agents. In: Woessner JF, Howell DS, eds. Joint cartilage degradation. New York: Marcel Dekker, 1993: 503-28

6 Pelletier JP, Martel-Pelletier J. Protective effects of corticosteroids on cartilage lesions and osteophyte formation in the Pond-Nuki dog mode of osteoarthritis. Arthritis Rheum 1989;32:181-93.

7 Pelletier JP, Mineau F, Raynauld JP, et al. Intraarticular injections with methylprednisolone acetate reduce osteoarthritic lesions in parallel with chondrocyte stromelysin synthesis in experimental osteoarthritis. Arthritis Rheum 1994;37:414-23.

8 Pelletier JP, Cloutier JM, Martel-Pelletier J. In vitro effects of NSAIDS and corticosteroids on the synthesis and secretion of interleukin 1 by human osteoarthritic synovial membranes. Agents Actions 1992;39: 181-92.

9 Keagy RD, Keim HA. Intra-articular steroid therapy: repeated use in patients with chronic arthritis. Am J Med Sci 1967;253:45-5

10 Gaffney K, Ledingham, Perry JD. Intra-articular triamcinolone hexacetonide in knee osteoarthritis: factors influencing the clinical response. Ann Rheum Dis 1995:54:379-81.

11 Raynauld JP. Clinical trials: impact of intraarticular steroid injections on the progression of knee osteoarthritis. Osteoarthritis Cartilage 1999:7:348-9

12 Raynauld JP, Buckland-Wright C, Ward R, et al. Safety and efficacy of intra-articular steroid injections on the progression of knee osteoarthritis: a randomized double-blind, placebo-controlled trial. Arthritis Rheum 2003:48:370-7

13 Balch HW, Gibson JM, El-Ghobarey AF, et al. Repeated corticosteroid injections into knee joints. Rheumatol Rehabil 1977;16:137-40.

14 Dieppe PA, Sathapatayavongs B, Jones HE, et al. Intra-articular steroids in osteoarthritis. Rheumatol Rehabil 1980;19:212-17.

15 Friedman DM, Moore ME. The efficacy of intraarticular steroids in osteoarthritis: a double-blind study. J Rheumatol 1980;7:850-6.

16 Valtonen EJ. Clinical comparison of triamcinolonehexacetonide and betamethasone in the treatment of osteoarthrosis of the knee-joint. Scand $J$ Rheumatol 1981;41(suppl): 1-7.

17 Sambrook PN, Champion GD, Browne CD, et al. Corticosteroid injection for osteoarthritis of the knee: peripatellar compared to intra-articular route. Clin Exp Rheumatol 1989:7:609-13.

18 Cederlof S, Jonson G. Intraarticular prednisolone injection for osteoarthritis of the knee. A double blind test with placebo. Acta Chir Scand 1966;132:532-7.

19 Towheed TE, Hochberg MC. A systematic review of randomized controlled trials of pharmacological therapy in osteoarthritis of the knee, with an emphasis on trial methodology. Semin Arthritis Rheum 1997:26:755-70.

20 Jones A, Doherty M. Intra-articular corticosteroids are effective in osteoarthritis but there are no clinical predictors of response. Ann Rheum Dis 1996;55:829-32.

21 Brandt KD, Smith GN Jr, Simon LS. Intraarticular injection of hyaluronan as treatment for knee osteoarthritis - what is the evidence? Arthritis Rheum 2000,43:1 192-203.

22 Mandell BFF, Lipani J. Refractory osteoarthritis. Differential diagnosis and therapy. Rheum Dis Clin North Am 1995;21:163-78.

23 Balazs EA, Denlinger JL. Viscosupplementation: a new concept in the treatment of osteoarthritis. J Rheumatol 1993;39(suppl):3-9.
24 Grecomoro G, Piccione F, Letizia G. Therapeutic synergism between hyaluronic acid and dexamethasone in the intra-articular treatment of osteoarthritis of the knee: a preliminary open study. Curr Med Res Opin 1992:13:49-55.

25 Leardini G, Mattara L, Franceschini M, et al. Intra-articular treatment of knee osteoarthritis. A comparative study between hyaluronic acid and 6-methyl prednisolone acetate. Clin Exp Rheumatol 1991;9:375-81.

26 Leardini G, Franceschini M, Mattara L, et al. Intra-articular sodium hyaluronate in gonarthrosis. A controlled study comparing methylprednisolone acetate. Clinical Trials Journal 1987:24:341-50.

27 Pietrogrande V, Melanotte PL, D'Agnolo B, et al. Hyaluronic acid versus methylprednisolone intra-articularly injected for the treatment of osteoarthritis of the knee. Curr Ther Res 1991;50:691-701

28 Guidolin DD, Ronchetti IP, Lini E, et al. Morphological analysis of articular cartilage biopsies from a randomized, clinical study comparing the effects of 500-730 kDa sodium hyaluronate (Hyalgan) and methylprednisolone acetate on primary osteoarthritis of the knee. Osteoarthritis Cartilage 2001;9:371-81.

29 Adams ME, Atkinson MH, Lussier AJ, et al. The role of viscosupplementation with Hylan G-F 20 (Synvisc) in the treatment of osteoarthritis of the knee: a Canadian multicenter trial comparing hylan G-F 20 alone, hylan G-F 20 with non-steroidal anti-inflammatory drugs (NSAIDs) and NSAIDs alone. Osteoarthritis Cartilage 1995;3:213-25.

30 Bragantini A Cassini M. Controlled single-blind trial of intra-articulary injected hyaluronic acid in osteoarthritis of the knee. Clinical Trials Journal 1987; 24:333-40.

31 Dixon AS, Jacoby RK, Berry $\mathrm{H}$, et al. Clinical trial of intra-articular injection of sodium hyaluronate in patients with osteoarthritis of the knee. Curr Med Res Opin 1988;11:205-13.

32 Dougados $M$, Nguyen $M$, Listrat $V$, et al. High molecular weight sodium hyaluronate (hyalectin) in osteoarthritis of the knee: a 1 year placebo-controlled trial. Osteoarthritis Cartilage 1993;1:97-103.

33 Grecomoro G, Martorana U, Di Marco C. Intra-articular treatment with sodium hyaluronate in gonarthrosis: a controlled clinical trial versus placebo. Pharmatherapeutica 1987;5:137-41

34 Namiki O, Toyoshima H, Morisaki N. Therapeutic effect of intra-articular injection of high molecular weight hyaluronic acid on osteoarthritis of the knee. Int J Clin Pharm Ther Toxicol 1982;20:501-7.

35 Brandt KD, Block JA, Michalski JP, et al. Efficacy and safety of intraarticular sodium hyaluronate in knee osteoarthritis. ORTHOVISC Study Group. Clin Orthop 2001;385:130-43.

36 Brocq O, Tran G, Breuil V, et al. Hip osteoarthritis: short-term efficacy and safety of viscosupplementation by hylan G-F 20. An open-label study in 22 patients. Joint Bone Spine 2002;69:388-91.

37 Miltner $\mathrm{O}$, Schneider U, Siebert $\mathrm{C}$, et al. Efficacy of intraarticular hyaluronic acid in patients with osteoarthritis-a prospective clinical trial. Osteoarthritis Cartilage 2002;10:680.

38 Maheu $\mathbf{E}$. Hyaluronan in knee osteoarthritis. A review of the clinical trials with Hyalgan $\circledast$. Eur J Rheumatol Inflamm 1995;15:17-24.

39 Altman RD, Moskowitz R, The Hyalgan Study Group. Intra-articular sodium hyaluronate (Hyalgan) in the treatment of patients with osteoarthritis of the knee: a randomized clinical trial. J Rheumatol 1998;25:2203-12

40 Listrat V, Ayral X, Patarnello F, et al. Arthroscopic evaluation of potential structure modifying activity of hyaluronan (Hyalgan) in osteoarthritis of the knee. Osteoarthritis Cartilage 1997;5:153-60.

41 Henderson EB, Smith EC, Pegley F, et al. Intra-articular injections of $750 \mathrm{kD}$ hyaluronan in the treatment of osteoarthritis. A randomized single center double blind placebo-controlled trial of 91 patients demonstrating lack of efficacy. Ann Rheum Dis 1995:53:529-34.

42 Edelson R, Burks RT, Bloebaum RD. Short-term effects of knee washout for osteoarthritis. Am J Sports Med 1995;23:345-9.

43 Dahlberg L, Lohmander LS, Ryd L. Intraarticular injections of hyaluronan in patients with cartilage abnormalities and knee pain. A one year double blind, placebo controlled study. Arthritis Rheum 1994;37:521-8.

44 Lohmander LS, Dalen N, Englund G, et al. Intra-articular hyaluronan injections in the treatment of osteoarthritis of the knee: a randomised, double blind, placebo controlled multicentre trial. Hyaluronan Multicentre Trial Group. Ann Rheum Dis 1996;55:424-31.

45 Lussier A, Cividino AA, McFarlane CA, et al. Viscosupplementation with hylan for the treatment of osteoarthritis: findings from clinical practice in Canada. J Rheumatol 1996;23:1579-85.

46 Puttick MPE, Wade JP, Chalmers A, et al. Acute local reactions after intra-articular hylan for osteoarthritis of the knee. J Rheumatol 1995;22:1311-4

47 Pullman-Mooar S, Mooar P, Sieck M, et al. Are there distinctive inflammatory flares of synovitis after hyalan GF intra-articular injections? Arthritis Rheum 1999; 42(abstract):S295.

48 Scale D, Wobig M, Wolpert W. Viscosupplementation of osteoarthritic knees with hylan: a treatment schedule study. Curr Ther Res 1994;55:220-32

49 Luzar MJ, Altawil B. Pseudogout following intraarticular injection of sodium hyaluronate. Arthritis Rheum 1998:41:939-40.

50 Maillefert JF, Hirschhorn P, Pascaud F, et al. Acute attack of chondrocalcinosis after intraarticular injection of hyaluronan. Rev Rhum Engl Ed 1997;64:593-4

51 Altman RD. Intra-articular sodium hyaluronate in osteoarthritis of the knee. Semin Arthritis Rheum 2000;30(suppl 1):11-8.

52 Dougados $M$. Sodium hyaluronate therapy in osteoarthritis: arguments for a potential beneficial structural effect. Semin Arthritis Rheum 2000;30(suppl 1):19-25

53 Vajaradul Y. Double-blind clinical evaluation of intra-articular glucosamine in outpatients with gonarthrosis. Clin Ther 1981;3:336-43. 
54 Silveri F, Morosini P, Brecciaroli D, et al. Intra-articular injection of somatostatin in knee osteoarthritis: clinical results and IGF-1 serum levels. Int J Pharmacol Res 1994;14:79-85.

55 Rasaratnam I, Ryan P, Bowman L, et al. A double-blind placebo-controlled study of intra-articular pentosan polysulfate (cartrophen) in patients with gonarthrosis-laboratory and clinical findings. 8th APLAR Congress of Rheumatology. Osteoarthritis Cartilage 1996;4:vi-vii.

56 Tejeswar Rao P. Intra-articular chloroquine in rheumatoid and osteoarthritis of knee joint. J Indian Med Assoc 1977:69:193-5.

57 Tanaka S, Ito T. Intraarticular injection of mucopolysaccharide polysulfuric acid ester in the treatment of osteoarthritis of the hip joints. Nippon Geka Hokan 1976;45:289-97.

58 Kumar M, Dikshit OP. Intra-articular lactic acid solution in osteoarthritis. J Indian Med Assoc 1968:50:420-2.

59 Gristina AG, Pace NA, Kantor TG, et al. Intra-articular thio-tepa compared with depomedrol and procaine in the treatment of arthritis. $J$ Bone Joint Surg Am 1970;52:1603-10.

60 Langkilde M, Rossel I. Intra-articular use of cytostatica (thio-tepa, azetepa and osmium acid). Acta Rheumatol Scand 1967;13:92-100.

61 Huskisson EC, Scott J. Orgotein in osteoarthritis of the knee joint. Eur J Rheumatol Inflamm 1981:4:212-18.

62 Gammer W, Broback LG. Clinical comparison of orgotein and methylprednisolone acetate in the treatment of osteoarthrosis of the knee joint. Scand J Rheumatol 1984;13:108-12.

63 Mazieres B, Masquelier AM, Capron MH. A French controlled multicenter study of intraarticular orgotein versus intraarticular corticosteroids in the treatment of knee osteoarthritis: a one-year followup. J Rheumatol 1991;27(suppl):134-7.

64 Will R, Laing B, Edelman J, et al. Comparison of two yttrium-90 regimens in inflammatory and osteoarthropathies. Ann Rheum Dis 1992;51:262-5.

65 Edmonds J, Smart R, Laurent $R$, et al. A comparative study of the safety and efficacy of dysprosium- 165 hydroxide macro-aggregate and yttrium-90 silicate colloid in radiation synovectomy-a multicentre double blind clinical trial. Australian Dysprosium Trial Group. Br J Rheumatol 1994;33:947-53.
66 Reeves KD, Hassanein K. Randomized prospective double-blind placebo-controlled study of dextrose prolotherapy for knee osteoarthritis with or without ACL laxity. Altern Ther Health Med 2000;6:68-80.

67 Corbett M, Seifert MH, Hacking C, et al. Comparison between local injections of silicone oil and hydrocortisone acetate in chronic arthritis. BM 1970;i:24-5.

68 Wright V, Haslock DI, Dowson D, et al. Evaluation of silicone as an artificial lubricant in osteoarthrotic joints. BN 1971;ii:370-3.

69 Helal B, Karadi BS. Artificial lubrication of joints: use of silicone oil. Ann Phys Med 1968;9:334-40.

70 Dawes PT, Kirlew C, Haslock, I. Saline washout for knee osteoarthritis: results of a controlled study. Clin Rheumatol 1987;6:61-3.

71 Ike RW, Arnold WJ, Rothschild EW, et al. Tidal irrigation versus conservative medical management in patients with osteoarthritis of the knee: a prospective randomized study. Tidal Irrigation Cooperating Group. J Rheumatol 1992;19:772-9.

72 Ravaud P, Moulinier L, Giraudeau B, et al. Effects of joint lavage and steroid injection in patients with osteoarthritis of the knee: results of a multicenter, randomized, controlled trial. Arthritis Rheum 1999:42:475-82.

73 Creamer P, Hunt M, Dieppe P. Pain mechanisms in osteoarthritis of the knee: effect of intraarticular anesthetic. J Rheumatol 1996;23:1031-6.

74 Likar R, Schafer M, Paulak F, et al. Intraarticular morphine analgesia in chronic pain patients with osteoarthritis. Anesth Analg 1997:84:1313-17.

75 Stein A, Yassouridis A, Szopko C, et al. Intraarticular morphine versus dexamethasone in chronic arthritis. Pain 1999;83:525-32.

76 Papathanassiou NP. Intra-articular use of tenoxicam in degenerative osteoarthritis of the knee joint. J Int Med Res 1994;22:332-7.

77 Egsmose C, Lund B, Bach Andersen R. Hip joint distension in osteoarthrosis. A triple-blind controlled study comparing the effect of intra-articular indoprofen with placebo. Scand J Rheumatol $1984 ; 13: 238-42$

78 Moens B, Moens $\mathrm{CH}$. Intra-articular injection of phenylbutazone in gonarthrosis. Ann Rheum Dis 1986;45:788.

You can access the FULL TEXT of articles cited in Postgraduate Medical Journal online if the citation is to one of the more than 200 journals hosted by HighWire (http://highwire.stanford.edu) without a subscription to that journal. There are also direct links from references to the Medline abstract for other titles.

www.postgradmedj.com 